\title{
Morphological Characterization and DNA Barcoding of Duckweed Species in Saudi Arabia
}

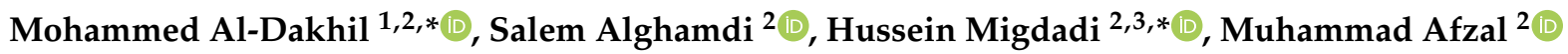 \\ and Ahmed Abdelrahim Ali ${ }^{2}$ \\ 1 Natural Resources and Environmental Research Institute, King Abdulaziz City for Science and Technology, \\ Riyadh 11442, Saudi Arabia \\ 2 Department of Plant Production, College of Food and Agriculture Sciences, King Saud University, \\ Riyadh 11451, Saudi Arabia; salem@ksu.edu.sa (S.A.); mmushtaq@ksu.edu.sa (M.A.); \\ arahim.eng@gmail.com (A.A.A.) \\ 3 National Agricultural Research Center, Baqa, Amman 19381, Jordan \\ * Correspondence: maaldakhil@kacst.edu.sa (M.A.-D.); hmigdadi@ksu.edu.sa (H.M.); \\ Tel.: +966-535-871-345 (H.M.)
}

check for updates

Citation: Al-Dakhil, M.; Alghamdi, S.; Migdadi, H.; Afzal, M.; Ali, A.A. Morphological Characterization and DNA Barcoding of Duckweed Species in Saudi Arabia. Plants 2021, 10, 2438. https://doi.org/10.3390/ plants10112438

Academic Editor: Alex Troitsky

Received: 13 September 2021

Accepted: 6 November 2021

Published: 12 November 2021

Publisher's Note: MDPI stays neutral with regard to jurisdictional claims in published maps and institutional affiliations.

Copyright: (c) 2021 by the authors. Licensee MDPI, Basel, Switzerland. This article is an open access article distributed under the terms and conditions of the Creative Commons Attribution (CC BY) license (https:/ / creativecommons.org/licenses/by/ $4.0 /)$.

\begin{abstract}
Duckweeds, or Lemnaceae, are widespread aquatic plants. Morphology-based identification of duckweed species is difficult because of their structural complexity. Hence, molecular tools provide significant advantages for characterizing and selecting species or clones for sustainable commercial use. In this study, we collected and characterized ten duckweed isolates from nine different regions in Saudi Arabia (SA). Based on the morphological characterization and phylogenetic analysis of intergenic spacer sequences of chloroplast DNA using six barcoding markers, the clones were classified into three genera, represented by seven species: Lemna gibba L., Lemna minor L., Lemna japonica Landolt, Lemna aequinoctialis Welw., Lemna perpusilla Torr., Spirodela polyryiza (L.) Schleid., and Landoltia punctate G. Mey. Lemna gibba was revealed to be a distinct dominant duckweed species in many regions of SA. Five barcoding markers showed that L. gibba, L. minor, and L. punctata were the most widely distributed species in the country. However, L. punctata, L. perpusilla, and S. polyryiza were the dominant species in the Al-Qassim, Madinah-1, and Madinah-2 regions, respectively. Moreover, the morphological traits revealed variations for these clones, relative to other studied duckweed clones. According to the results obtained in this study, three out of six plastid markers $(\operatorname{trn} \mathrm{H}-p s b \mathrm{~A}$, $m a t K$, and $a t p \mathrm{~F}-a t p \mathrm{H}$ ) helped to identify the dominant duckweed species in Saudi Arabia. Further evaluation based on adaptability, molecular genetic studies, and functional genomics is needed for these species to be used at the commercial level in Saudi Arabia.
\end{abstract}

Keywords: duckweeds; identification; morphological; DNA barcoding; phylogenetic analysis

\section{Introduction}

Under the arid conditions of Saudi Arabia, the agricultural sector plays a significant role in food security for humans and animals, as well as economic, social, and sustainable development. Saudi Arabia, with a Vision 2030 strategic plan, aims to enact sustainable development in food production by saving freshwater resources, the environment, and energy. The government supports research on new feed resources for livestock and poultry that maintain high protein value and high water and fertilizer use efficiency. Duckweed is an aquatic plant that contains crude protein up to $45 \%$ of its dry weight under optimum conditions and may be used, without further processing, as a complete feed for animals and fish [1]. Duckweed starch content has been reported to be from 5\% to $70 \%$ of its dry weight. The high level of starch and low lignin and cellulose levels make duckweed a promising feedstock for biofuel production [2]. Duckweed plants float on the surface or are slightly submerged in water. Leaf-like fronds are modified leaves and stem that mainly function in photosynthesis and vegetative reproduction. As a result, the rate of biomass production is 
high, providing the basis for various practical applications of duckweed in food and feed sustainability [3]. For commercial utilization of duckweed, knowledge of its taxonomy is required. At the morphological level, delineating duckweed species has been shown to be difficult. Many studies have tried to decrease the anatomical complexity based on the chemical composition of flavonoids [4] and to delineate duckweed species using allozyme, which has helped advance morphology techniques $[5,6]$. The genome size of duckweed varies 13-fold, ranging from $150 \mathrm{Mb}$ in Spirodela polyrhiza (L.), Schleid. to $1881 \mathrm{Mb}$ in Wolffia arrhiza Wimm. With the development of sequencing technology and bioinformatics, $\mathrm{m}$ genomes from Spirodela and Lemna have been sequenced and assembled [7]. Thirty-eight duckweed species have been identified and characterized [8]. With molecular biology tools and techniques (polymerase chain reaction and Q-PCR, DNA barcoding, and highthroughput DNA sequencing tools), a taxonomic analysis at the molecular level offers a more profound understanding than chemotaxonomy. Therefore, among the various DNA analysis methods for taxonomic definition, molecular taxonomy is considered the most suitable method for identifying and evaluating the genetic potential of duckweed species [9]. There are only a few studies in the literature on identifying duckweed genera and species in Saudi Arabia. Masrahi et al. [10] reported the first record of Wolffiella hyalina (Delile) Monod in Saudi Arabia and regarded it as an addition to the flora of Saudi Arabia. The present study aimed to assess the genetic variability based on morphological traits and molecular (DNA barcoding) markers among duckweed clones collected from $\mathrm{m}$

\section{Results}

The identification of duckweed clones, collected from ten locations in Saudi Arabia, was made through morphological and molecular characterization (Figure 1). Morphological variation was recorded based on the different measurements (Tables 1 and 2). All clones showed obovate fronds shape and rounded frond apex, and the turions were present. The frond shape of the clones from the Riyadh, Taif, Tohama, Tanomah, Qassim, and Madinah-1 regions was asymmetric, while those from the remaining regions were symmetric. The frond color of clones from five regions (Riyadh, Tohama, Al-Baha, Qassim, and Madinah-1) were dark green, and, in five regions (Taif, Jazan, Tanomah, Dhahran, and Madinah-2), the frond color was recorded as light green. All the studied duckweed clones showed frond apexes and turions. The analysis of variance for frond and root traits showed highly significant differences among the clones (Table 2). The number of roots ranged from 1.67 to 9.22; moreover, the Madinah-2 and Al-Qassim clones had the highest number of roots and differed significantly from other clones. The maximum number of roots, i.e., 9.22, was recorded for the Madinah-2 clones, while the Al-Baha clones had the lowest number of roots, i.e., 1.67. The Tanomah clones had the longest roots $(3.76 \mathrm{~mm})$, and the Madinah-2 clones had the shortest roots $(0.74 \mathrm{~mm})$. Regarding the characteristics of fronds, clones collected from the Al-Qassim region had the highest number of fronds (6.0), while clones from the Riyadh region had the longest fronds $(7 \mathrm{~mm})$. The widest and thickest clones were $8.5 \mathrm{~mm}$ from the Madinah- 1 region and $3.2 \mathrm{~mm}$ from the Al-Taif region, respectively. 


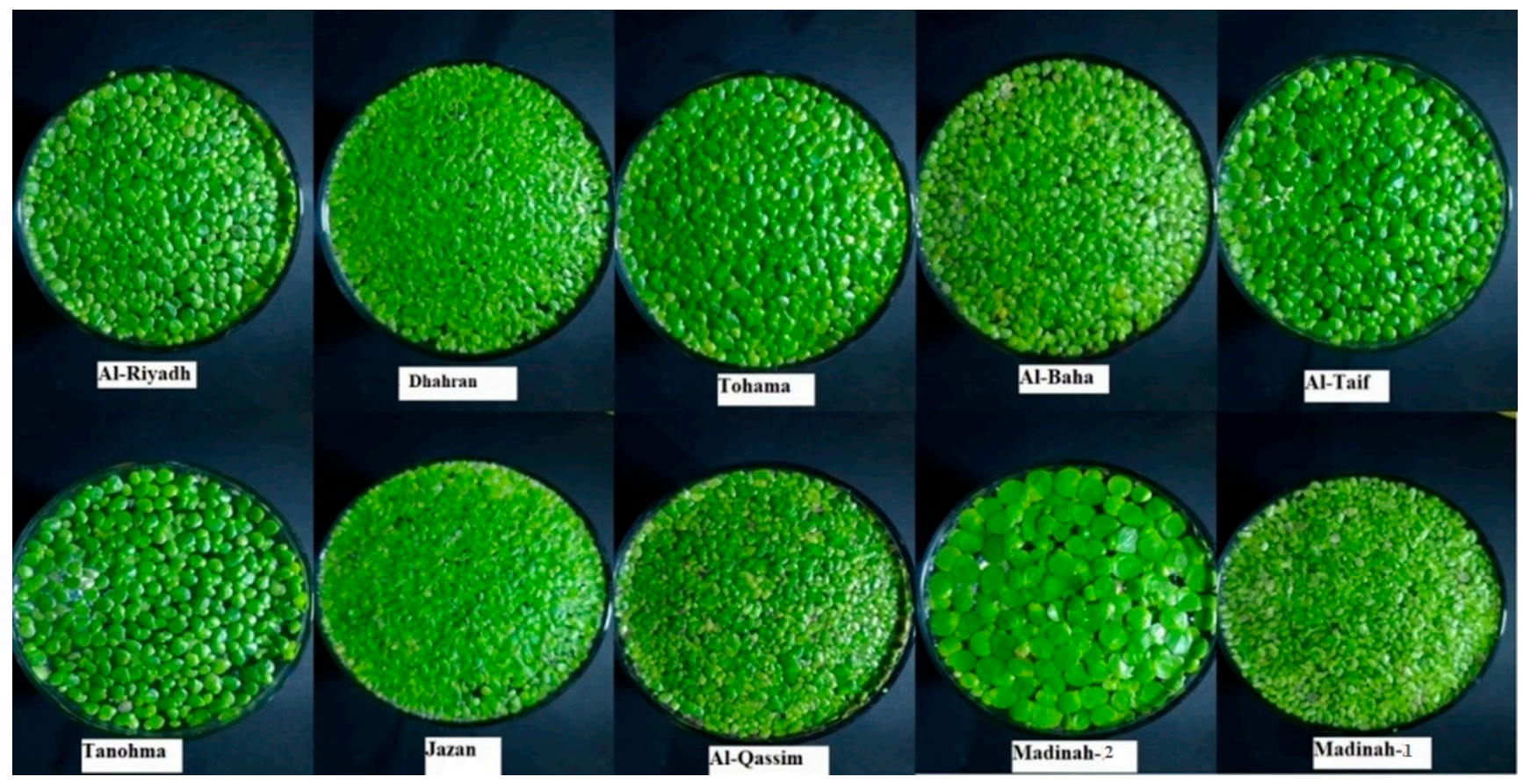

Figure 1. Duckweed clones collected from Saudi Arabia were used for morphological characterization and molecular identification.

Table 1. Qualitative morphological traits for studied duckweed clones of the ten locations of Saudi Arabia ( $n=10$ samples from each clone averaged and replicated three times, total samples $=30$ reads). Frond shape-FSh; frond symmetry-FS; frond color-FC; frond apex-FA; turions-T.

\begin{tabular}{cccccc}
\hline & FSh & FS & FC & FA & T \\
\hline Riyadh & Obovate & Asymmetry & Dark Green & Rounded & Present \\
Dhahran & Obovate & Symmetry & Light Green & Rounded & Present \\
Tohama & Obovate & Asymmetry & Dark Green & Rounded & Present \\
Al-Baha & Obovate & Symmetry & Dark Green & Rounded & Present \\
Al-Taif & Obovate & Asymmetry & Light Green & Rounded & Present \\
Tanomah & Obovate & Asymmetry & Light Green & Rounded & Present \\
Jazan & Obovate & Symmetry & Light Green & Rounded & Present \\
Al-Qassim & Obovate & Asymmetry & Dark Green & Rounded & Present \\
Madinah-1 & Obovate & symmetry & Light Green & Rounded & Present \\
Madinah-2 & Obovate & Asymmetry & Dark Green & Rounded & Present \\
\hline
\end{tabular}

To facilitate interpretation of the correlation matrix, produced from the quantitative and qualitative morphological traits for ten duckweed clones, a principal component analysis (PCA) was applied. The PCA plots provided a visual overview of how different traits influenced the distribution of the duckweed clones. The first three principal components explained $88.27 \%$ of the total variance (i.e., PC1 46.4\%, PC2 24.3\%, and PC3 17.51\%). The plot for the PC1 and PC2 showed that some traits described the same variation among the clones (Figure 2). The number of roots formed the underlying dimension for PC1, with a value of 0.95 positive loadings; whereas, frond width $(-0.2)$ was negatively loaded and placed on the left-hand side of the plot. PC2 explained $24.3 \%$ of the variance and showed a positive correlation with frond traits, such as frond length (0.79), number of fronds (0.26), and frond thickness (0.22), besides root length (0.26). PC3 was loaded with frond width with positive loading (0.76). The Al-Qassim and Madina-2 clones showed the most positive loading in PC1, with 4.9 and 5.8, respectively, while Madina-1 clones had the most negative loading on PC1 and PC2. Those clones were considered to be the most divergent clones. 
Table 2. Analysis of variance (ANOVA) for the quantitative morphological traits of the studied duckweed clones. Mean and standard deviation of the evaluated traits $(n=10$ samples and three replications, total $=30)$.

\begin{tabular}{cccccccc}
\hline & $\begin{array}{c}\text { Number of } \\
\text { Roots }\end{array}$ & $\begin{array}{c}\text { Frond Width } \\
\mathbf{( m m )}\end{array}$ & $\begin{array}{c}\text { Frond } \\
\text { Thickness } \\
\mathbf{( m m )}\end{array}$ & $\begin{array}{c}\text { Frond } \\
\text { Length } \mathbf{( m m})\end{array}$ & $\begin{array}{c}\text { NCF } \\
\text { Number of } \\
\text { Contiguous } \\
\text { Fronds }\end{array}$ & $\begin{array}{c}\text { Root Length } \\
(\mathbf{m m})\end{array}$ & $\begin{array}{c}\text { Number of } \\
\text { Fronds }\end{array}$ \\
\hline Riyadh & $2.00 \pm 0.01 \mathrm{~b}$ & $5.7 \pm 0.12 \mathrm{~b}$ & $2.3 \pm 0.17 \mathrm{c}$ & $7.0 \pm 0.02 \mathrm{a}$ & $4.0 \pm 0.01 \mathrm{~b}$ & $2.35 \pm 0.13 \mathrm{~b}$ & $4.00 \pm 0.01 \mathrm{~b}$ \\
Al-Taif & $2.00 \pm 0.01 \mathrm{~b}$ & $5.8 \pm 0.06 \mathrm{~b}$ & $3.2 \pm 0.06 \mathrm{a}$ & $6.5 \pm 0.06 \mathrm{~b}$ & $5.0 \pm 0.01 \mathrm{a}$ & $2.02 \pm 0.32 \mathrm{~b}$ & $3.67 \pm 0.50 \mathrm{~b}$ \\
Tohama & $3.00 \pm 0.01 \mathrm{~b}$ & $5.8 \pm 0.06 \mathrm{~b}$ & $3.0 \pm 0.00 \mathrm{~b}$ & $6.5 \pm 0.04 \mathrm{~b}$ & $3.0 \pm 0.01 \mathrm{c}$ & $2.29 \pm 0.37 \mathrm{~b}$ & $4.00 \pm 0.01 \mathrm{~b}$ \\
Jazan & $2.44 \pm 0.53 \mathrm{~b}$ & $3.5 \pm 0.10 \mathrm{~d}$ & $0.5 \pm 0.06 \mathrm{f}$ & $4.6 \pm 0.04 \mathrm{e}$ & $3.0 \pm 0.01 \mathrm{c}$ & $0.84 \pm 0.05 \mathrm{c}$ & $3.67 \pm 0.50 \mathrm{~b}$ \\
Tanomah & $1.89 \pm 0.33 \mathrm{~b}$ & $3.4 \pm 0.06 \mathrm{~d}$ & $0.5 \pm 0.0 \mathrm{f}$ & $4.5 \pm 0.09 \mathrm{e}$ & $4.0 \pm 0.01 \mathrm{~b}$ & $3.76 \pm 0.49 \mathrm{a}$ & $3.56 \pm 0.53 \mathrm{~b}$ \\
Al-Baha & $1.67 \pm 0.50 \mathrm{~b}$ & $3.5 \pm 0.06 \mathrm{~d}$ & $1.0 \pm 0.0 \mathrm{~d}$ & $4.7 \pm 0.09 \mathrm{e}$ & $4.0 \pm 0.01 \mathrm{~b}$ & $1.98 \pm 0.45 \mathrm{~b}$ & $3.00 \pm 0.01 \mathrm{bc}$ \\
Dhahran & $2.00 \pm 0.01 \mathrm{~b}$ & $3.0 \pm 0.01 \mathrm{e}$ & $0.4 \pm 0.0 \mathrm{f}$ & $5.0 \pm 0.07 \mathrm{~d}$ & $3.0 \pm 0.01 \mathrm{c}$ & $1.54 \pm 0.28 \mathrm{~b}$ & $3.22 \pm 0.44 \mathrm{bc}$ \\
Al-Qassim & $8.11 \pm 0.78 \mathrm{a}$ & $4.0 \pm 0.01 \mathrm{c}$ & $0.7 \pm 0.0 \mathrm{e}$ & $6.0 \pm 0.06 \mathrm{c}$ & $5.0 \pm 0.01 \mathrm{a}$ & $2.14 \pm 0.09 \mathrm{~b}$ & $6.00 \pm 0.01 \mathrm{a}$ \\
Madinah-1 & $2.00 \pm 0.01 \mathrm{~b}$ & $8.5 \pm 0.01 \mathrm{a}$ & $0.9 \pm 0.0 \mathrm{~d}$ & $1.0 \pm 0.06 \mathrm{~g}$ & $4.0 \pm 0.01 \mathrm{~b}$ & $0.84 \pm 0.09 \mathrm{c}$ & $2.89 \pm 0.33 \mathrm{bc}$ \\
Madinah-2 & $9.22 \pm 2.39 \mathrm{a}$ & $4.0 \pm 0.06 \mathrm{c}$ & $0.4 \pm 0.0 \mathrm{f}$ & $4.0 \pm 0.05 \mathrm{f}$ & $3.0 \pm 0.01 \mathrm{c}$ & $0.74 \pm 0.09 \mathrm{c}$ & $2.44 \pm 0.53 \mathrm{bc}$ \\
\hline Tukey HSD & 1.60 & 0.38 & 0.18 & 0.45 & 0.42 & 0.60 & 1.10 \\
\hline
\end{tabular}

Means followed with the same letter in the column were not significantly different based on Tukey HSD, $p<0.05$.

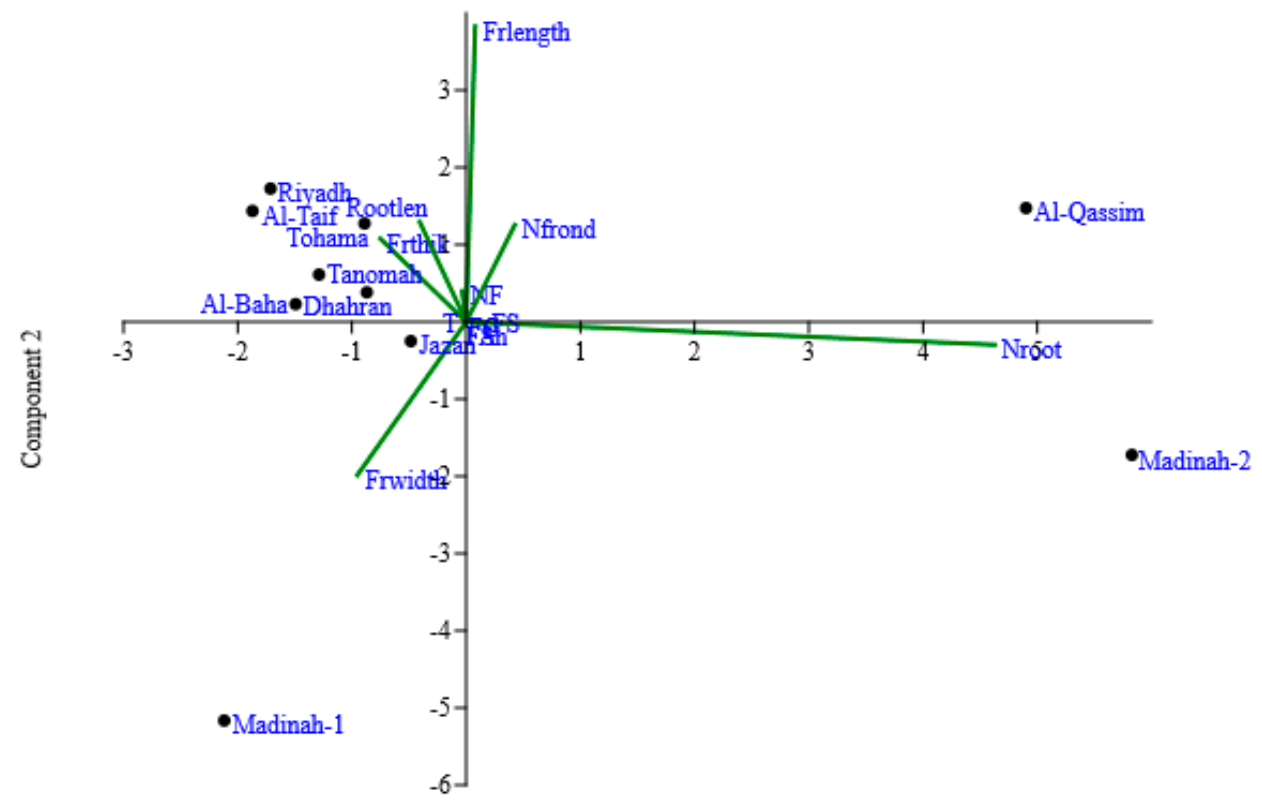

Component 1

Figure 2. Two-dimensional biplot ordination of the duckweed clones on principal component axes according to qualitative and rescaled quantitative data traits. Principal component 1 (PC1) represented $46.4 \%$ of the total variance, and PC2 represented $24.3 \%$ of the total variance. Frond shape (FSh); frond symmetry (FS); frond color (FC); frond apex (FA); turions (T); the number of roots-Nroot; frond width-Frwidth; frond thickness (Frthick); frond length (Frlength); the number of contiguous fronds (NCF); root length (Rootlen); the number of fronds (Nfrond).

The results generated from the six plastid markers ( $p s b \mathrm{~K}-p s b \mathrm{I}, \operatorname{trn} \mathrm{H}-p s b \mathrm{~A}, \operatorname{at} p \mathrm{~F}-a t p \mathrm{H}$, $m a t \mathrm{~K}, r p o \mathrm{C} 1$, and $r b c \mathrm{~L}$ ) for species identification, and their accessions numbers, are presented in Table 3, and the sequences generated from each sample are shown in Supplementary Table S1. The clones collected from the Riyadh, Dhahran, Tohama, AlBaha, Al-Taif, and Tanomah regions represented the same species (Table 3). However, the duckweed clones collected from the Jazan region represented L. aequinoctialis, and all the sequence data markers confirmed its exact identification, except that $r b c \mathrm{~L}$ identified L. minor. Similarly, clones collected from the Al-Qassim and Madinah (Madinah-1 and Madinah-2) regions were identified as L. punctata, L. perpusilla, and S. polyryiza, respectively. 
Table 3. DNA barcoding-based identifications and accessions number among 10 duckweeds clones.

\begin{tabular}{|c|c|c|c|c|c|c|}
\hline Region & $p s b \mathrm{~K}-p s b \mathbf{I}$ & $\operatorname{trn} \mathrm{H}-p s b \mathrm{~A}$ & matK & $a t p \mathrm{~F}-a t p \mathbf{H}$ & rpoС1 & $r b c \mathrm{~L}$ \\
\hline Riyadh & $\begin{array}{c}\text { L. japonica } \\
\text { (OK546023) }\end{array}$ & $\begin{array}{c}\text { L. gibba } \\
\text { (OK103562) }\end{array}$ & $\begin{array}{c}\text { L. gibba } \\
\text { (OK095301) }\end{array}$ & $\begin{array}{c}\text { L. gibba } \\
\text { (OK095300) }\end{array}$ & $\begin{array}{c}\text { L. minor } \\
\text { (OK376426) }\end{array}$ & $\begin{array}{c}\text { L. gibba } \\
\text { (OK571367) }\end{array}$ \\
\hline Dhahran & $\begin{array}{c}\text { L. japonica } \\
\text { (OK571365) }\end{array}$ & $\begin{array}{c}\text { L. gibba } \\
\text { (OK383787) }\end{array}$ & $\begin{array}{c}\text { L. gibba } \\
\text { (OK375248) }\end{array}$ & $\begin{array}{c}\text { L.gibba } \\
\text { (OK598953) }\end{array}$ & $\begin{array}{c}\text { L. gibba } \\
\text { (Ok546019) }\end{array}$ & $\begin{array}{c}\text { L. gibba } \\
\text { (OK598946) }\end{array}$ \\
\hline Tohama & $\begin{array}{c}\text { L. japonica } \\
\text { (OK350360) }\end{array}$ & $\begin{array}{c}\text { L. gibba } \\
\text { (OK383788) }\end{array}$ & $\begin{array}{c}\text { L. gibba } \\
\text { (OK546020) }\end{array}$ & $\begin{array}{c}\text { L. gibba } \\
\text { (OK598959) }\end{array}$ & $\begin{array}{c}\text { L. minor } \\
\text { (OK376427) }\end{array}$ & $\begin{array}{c}\text { L. gibba } \\
\text { (OK598947) }\end{array}$ \\
\hline Al-Baha & $\begin{array}{c}\text { L. japonica } \\
\text { (OK350359) }\end{array}$ & $\begin{array}{c}\text { L. gibba } \\
\text { (OK103563) }\end{array}$ & $\begin{array}{c}\text { L. gibba } \\
\text { (OK571364) }\end{array}$ & & $\begin{array}{c}\text { L. minor } \\
(\mathrm{OK} 493446)\end{array}$ & $\begin{array}{c}\text { L. gibba } \\
\text { (OK598949) }\end{array}$ \\
\hline Jazan & $\begin{array}{l}\text { L. perpusilla } \\
\text { (OK350358) }\end{array}$ & $\begin{array}{l}\text { L. aequinoctialis } \\
\text { (OK383786) }\end{array}$ & $\begin{array}{l}\text { L. aequinoctialis } \\
(\mathrm{OK} 375249)\end{array}$ & $\begin{array}{l}\text { L. aequinoctialis } \\
\text { (OK598956) }\end{array}$ & $\begin{array}{l}\text { L. aequinoctialis } \\
\text { (OK493447) }\end{array}$ & $\begin{array}{c}\text { L. minor } \\
\text { (OK598948) }\end{array}$ \\
\hline Al-Taif & $\begin{array}{c}\text { L. japonica } \\
\text { (OK546024) }\end{array}$ & $\begin{array}{c}\text { L. gibba } \\
\text { (OK383789) }\end{array}$ & $\begin{array}{c}\text { L. gibba } \\
\text { (OK546021) }\end{array}$ & $\begin{array}{c}\text { L. gibba } \\
\text { (OK598958) }\end{array}$ & $\begin{array}{c}\text { L. gibba } \\
\text { (OK } 493448)\end{array}$ & $\begin{array}{c}\text { L. gibba } \\
\text { (OK598951) }\end{array}$ \\
\hline Tanomah & $\begin{array}{c}\text { L. japonica } \\
\text { (OK350361) }\end{array}$ & $\begin{array}{c}\text { L. gibba } \\
\text { (OK383790) }\end{array}$ & $\begin{array}{c}\text { L. gibba } \\
\text { (OK546026) }\end{array}$ & $\begin{array}{c}\text { L. gibba } \\
\text { (OK598957) }\end{array}$ & $\begin{array}{c}\text { L. minor } \\
\text { (OK493449) }\end{array}$ & $\begin{array}{c}\text { L. gibba } \\
\text { (OK598952) }\end{array}$ \\
\hline Al-Qassim & $\begin{array}{l}\text { L. punctata } \\
\text { (OK350363) }\end{array}$ & $\begin{array}{c}\text { L. punctata } \\
\text { (OK247674) }\end{array}$ & $\begin{array}{l}\text { L. punctata } \\
\text { (OK375250) }\end{array}$ & $\begin{array}{c}\text { L. punctata } \\
\text { (OK598955) }\end{array}$ & $\begin{array}{c}\text { L. punctata } \\
\text { (OK493450) }\end{array}$ & $\begin{array}{c}\text { L. punctata } \\
\text { (OK571368) }\end{array}$ \\
\hline Madinah-1 & $\begin{array}{l}\text { L. perpusilla } \\
\text { (OK350362) }\end{array}$ & $\begin{array}{l}\text { L.aequinoctialis } \\
\text { (OK571366) }\end{array}$ & $\begin{array}{l}\text { L.aequinoctialis } \\
\text { (OK546022) }\end{array}$ & $\begin{array}{l}\text { L. aequinoctialis } \\
\text { (OK598954) }\end{array}$ & $\begin{array}{l}\text { L. aequinoctialis } \\
\text { (OK493451) }\end{array}$ & $\begin{array}{c}\text { L. minor } \\
\text { (OK571369) }\end{array}$ \\
\hline Madinah-2 & $\begin{array}{l}\text { S. polyryiza } \\
\text { (OK546025) }\end{array}$ & $\begin{array}{l}\text { S. polyryiza } \\
\text { (OK247675) }\end{array}$ & - & $\begin{array}{l}\text { S. polyryiza } \\
\text { (OK247676) }\end{array}$ & $\begin{array}{l}\text { S. polyryiza } \\
\text { (OK493452) }\end{array}$ & $\begin{array}{l}\text { S. polyryiza } \\
\text { (OK598950) }\end{array}$ \\
\hline
\end{tabular}

After sequencing, the data were cleaned and aligned using the Bioedit software, and the species-level phylogenetic tree was constructed. According to the six markers, the duckweed clones, isolated from the Riyadh region, were identified as L. gibba by four markers $(t r n \mathrm{H}-p s b \mathrm{~A}$, mat $\mathrm{K}$, at $p \mathrm{~F}-a t p \mathrm{H}$, and $r b c \mathrm{~L})$, while L. japonica was recognized by

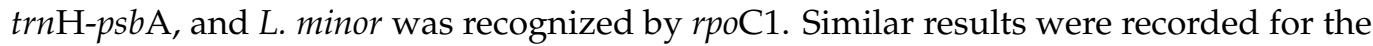
Dhahran, Tohama, Al-Baha, Al-Taif, and Tanomah regions. Most markers identified the Jazan isolate as L. aequinoctialis, but it was identified as L. minor only by the $r b c L$ marker. However, the duckweed clones isolated from Al-Qassim and Madinah-2 were identified as L. punctata and S. polyryiza by all markers, respectively. The clones from Madinah-1 were identified as L. perpusilla with three markers ( $p s b \mathrm{~K}-p s b \mathrm{I}, \operatorname{trn} \mathrm{H}-p s b \mathrm{~A}$, and matK). In comparison, two markers (atp F-atpH and $r p o \mathrm{C} 1)$ identified the isolate as L. aequinoctialis, and $r b c \mathrm{~L}$ identified it as L. minor. Based on multiple nucleotide sequence alignment (Figure S1), divergence score matrix (Figure S2), and the phylogenetic tree (Figure 3), four species were mostly distributed in Saudi Arabia, which were L. gibba, L. aequinoctialis, L. punctata, and S. polyryiza (Figure 3). 


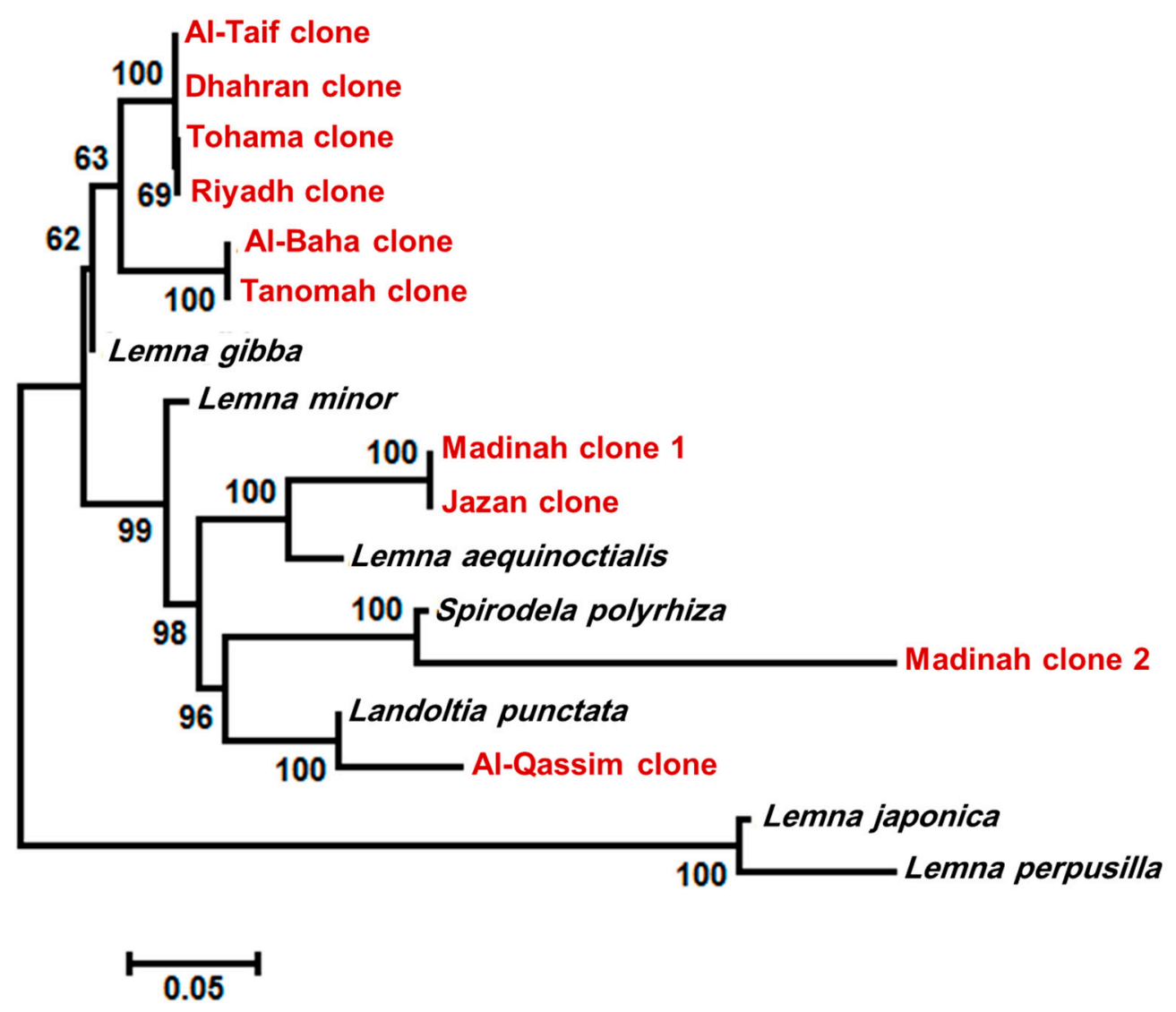

Figure 3. Phylogenetic tree based on maximum likelihood methods with 1000 bootstraps constructed in MEGA 10.0 using the concatenated sequences of $p s b \mathrm{~K}-p s b \mathrm{I}, t r n \mathrm{H}-p s b \mathrm{~A}$, and $a t p \mathrm{~F}-a t p \mathrm{H}$ intergenic spacer region, and $m a t \mathrm{~K}, r p o \mathrm{C} 1$, and $r b c \mathrm{~L}$ gene. The numbers on the nodes represent the percentage of bootstrap values from 1000 replicates. The genetic distances are indicated by the horizontal bar.

\section{Discussion}

Out of seven different haplotypes identified, four were dominant in the ten regions, identified using DNA barcoding and phylogenetic analysis. The frond shape, frond apex, and turions registered the same obovate, rounded, and present, respectively, for all duckweeds clones. In this study, the number of roots and frond length significantly contributed to the genetic variability among collected clones, confirming that they were the most influential variability components. A similar morphological identification was made earlier by [11] using morphological characterization for species identification among duckweed. This grouping included S. polyrhiza, L. aequinoctialis, L. punctata, and W. globose. It was also suggested that the low degree of differentiation among members of the Lemnaceae family most likely owes to adaptation to the highly specialized way of aquatic life [12].

Similar results were reported by Azer [13], who classified the Lemna genus into three different clusters, based on morphological characterization. The first cluster included L. gibba and L. minor, while the second and third clusters included L. trisulca and L. aequinoctialis. Bog et al. [14] classified the Lemna genus into four sections. It was also suggested that the similarities in specific morphological characteristics were closely connected to L. gibba and L. minor. A molecular study based on DNA barcoding results also recorded L. japonica, L. gibba, and L. minor aggregated in the same group. However, the phylogenetic analysis confirmed this relationship and reported that L. japonica, L. gibba, and L. minor were present in the same group. 
We can infer that the samples collected from the Riyadh, Dhahran, Tohama, Al-Baha, Al-Taif, and Tanomah regions had similar traits (morphological characterization). The traits include long roots, having many fronds with veins that inflate, and few seeds ribbed with L. minor and fewer with L. gibba, but not in L. aequinoctialis and L. trisulca [14]. Our study recorded similar results-i.e., samples collected from the Qassim, Madinah-1, and Madinah-2 regions belonged to three different genera and recorded unique characteristics. relative to other duckweed strains. In contrast, a detailed key is available for identifying species based on morphological traits [11]. A lack of experience and expertise in morphological taxonomy limits using this key to identify duckweed species worldwide. We also used six different plastid markers to identify duckweed species in Saudi Arabia because of limited morphological markers.

Similarly, Klaus et al. [15] suggested that plastid spacer barcoding markers have shown to be reliable tools for identifying duckweed species, especially when used in conjunction with several markers. However, all clones of the same species cannot be differentiated by these markers alone. In this context, several other plastid and mitochondrial markers are good options for obtaining excellent results [8,16], or another global marker (i.e., AFLP) could serve the purpose [14]. Zhang and Azizullah [17] stated that, although duckweeds can occasionally be found in single or more complex communities, they often exist in two or three species communities. Using ISSR markers to assess the genetic variability in populations of seven species in genus Lemna and Spirodela from China and Vietnam, Xue et al. [18] reported genetic differentiation of duckweeds, suggesting that geographic differentiation had a significant influence on the genetic diversity of duckweeds. In a previous report, duckweed clones from tropical Africa showed higher genetic diversity than those from other regions, probably because of higher temperatures and radiation in the equatorial region [19].

A comprehensive phylogenetic analysis has also been carried out using the morphological, anatomical characters, flavonoids, and molecular analysis (chloroplast and introns) sequences were used to classify the Lemnaceae species and phylogenetic analysis confirms the lemna, landoltia, spirodela, wolffian, and wolffiella in the grouping [20]. The current study also identifies similar results, i.e., L. gibba, L. minor, L. japonica, and L. aequinoctialis using the morphological and molecular combined data. Wang et al. [8] reported delineating the genus Lemna, based on several plastid sequences. Tippery et al. [21] also investigated the use of various plastid and nuclear markers (ETS and ITS), and Borisjuk et al. [22] used $p s b \mathrm{~K}-p s b \mathrm{I}$ and $a t p \mathrm{~F}-a t p \mathrm{H}$. Similar results were recorded during our study, L. gibba, L. minor, and L. japonica (Riyadh, Dhahran, Tohama, and Al-Baha), while other clones were recorded in different genera (L. perpusilla/L. aequinoctialis, L. punctata, S. polyryiza) using the plastid markers. Landolt [23] assigned the highest morphological primitiveness to L. gibba, while the lowest was assigned to L. minuta and L. valdiviana, which possibly signifies the genus Lemna as the basal species, while the latter represents the most derived species. In several projects, most Lemna species could be easily identified using DNA barcoding.

$\mathrm{Xu}$ et al. [24] suggested that duckweeds were the only occasionally observed aquatic plants present in large reservoirs and natural rivers. Our observations show that L. aequinoctialis is the best candidate for future regeneration applications in the Jazan region, where samples are collected from rain pools (a small area of still water, typically one formed naturally), usually receive heavy rain during the year. These pools are distributed on top of mountains and are, perhaps, the best among the pool. The genus Lemna has been studied for several years. However, the taxonomic identification boundaries are not yet adequately resolved, and there are still several botanists who disagree with the identification of Lemna species. Most of its features are changed and significantly overlap. Because of the variability of this genus, taxonomists have had controversy for over a century and treated the Lemna genus into several species [14,25]. It is known that S. punctata, S. intermedia, and S. polyrhiza represent the same genus, called Spirodela [23]. According to morphological traits, $S$. intermedia is the most primitive Lemnaceae species, and the highest primitiveness is found in this species [9]. By applying molecular tools for taxonomy to the Lemnaceae family, 
these three species were separated into two different genera, i.e., Spirodela and Landoltia (changing the nomenclature of the species S. punctata to L. punctata), after the analysis of the plastid $r b c L$ sequence [26]. The next generation sequencing technique may be considered, since it is less expensive; additionally, the entire chloroplast genome opens a new avenue to resolve species identification issues. Recent advances in organelles [8] and sequencing of nuclear genomes [27] could mine potential markers further.

According to the rps16 data of [16], the $W$. globosa grouping is composed of the six genera of the W. globosa species. While the plastid markers $r p 16$ and atpF-atpH showed genetic differences in L. aequinoctialis and W. globosa recorded relatively low diversity in a cosmopolitan environment [28], it is questionable if a longer sequence of clones would significantly increase this genetic diversity. While the genetic background of these clones was also widely distributed, S. polyrhiza was dispersed. The geographical influence on genetic diversity appears to be higher, as variation was found among all duckweed clones in the Jazan south region compared with clones in the northern regions, especially in the L. aequinoctialis species [24]. Our results recorded that the exact geographical positions (Qassim (L. punctata), Madinah-1 (L. perpusilla), Madinah-2 (S. polyryiza)), met the geographic environment. The lower latitude and higher temperatures, and ultraviolet radiation to the south of the Hainan Island could be responsible for this similarity [29]. The presence of L. punctata, L. perpusilla, and S. polyryiza could also contribute to their widespread distribution and adaptability to different environmental conditions in the region.

\section{Materials and Methods}

\subsection{Plant Material}

The duckweed clones analyzed in this study were collected from ten different regions of Saudi Arabia (Figure 4). The plants were rinsed in clean water, cultured in half-strength Hoagland solution, and acclimated for one week before starting the experiments. A single plant from each clone was cultured at $28^{\circ} \mathrm{C}$, in $14 \mathrm{~h}$ of light per day, for two weeks for multiplication (Figure 1). The study was conducted at the greenhouse of the College of Food and Agriculture Sciences, King Saud University, Riyadh, Saudi Arabia.

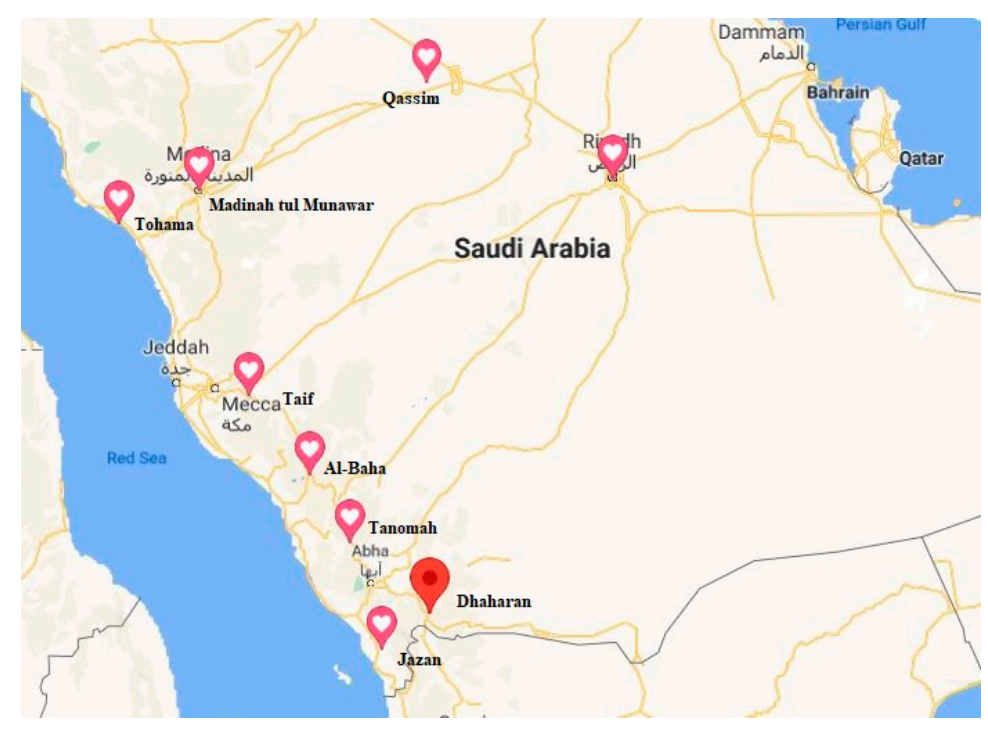

Figure 4. Saudi duckweed collection sites. The latitude (N), longitude (E), and altitude in meters of the locations are as follows: Riyadh $\rightarrow 24^{\circ} 39^{\prime} 31^{\prime \prime} \rightarrow 46^{\circ} 36^{\prime} 26^{\prime \prime} \rightarrow 614$; Dhahran $\rightarrow 17^{\circ} 40^{\prime} 36^{\prime \prime}$ $\rightarrow 43^{\circ} 20^{\prime} 53^{\prime \prime} \rightarrow 1717$; Tohama $\rightarrow 19^{\circ} 48^{\prime} 52.4^{\prime \prime} \rightarrow 41^{\circ} 37^{\prime} 14.6^{\prime \prime} \rightarrow 2070 ;$ Al-Baha $\rightarrow 20^{\circ} 00^{\prime} 46.3^{\prime \prime} \rightarrow 41^{\circ} 29^{\prime} 12^{\prime \prime}$ $\rightarrow 2103$; Jazan $\rightarrow 17^{\circ} 01^{\prime} 56^{\prime \prime} \rightarrow 43^{\circ} 09^{\prime} 04^{\prime \prime} \rightarrow 947 ; \quad$ Al-Taif $\rightarrow 21^{\circ} 12^{\prime} 45^{\prime \prime} \rightarrow 40^{\circ} 27^{\prime} 17^{\prime \prime} \rightarrow 1672 ; \quad$ Tanomah $\rightarrow 18^{\circ} 54^{\prime} 37.2^{\prime \prime} \rightarrow 42^{\circ} 12^{\prime} 29.4^{\prime \prime} \rightarrow 2228$; Al-Qassim $\rightarrow 26^{\circ} 24^{\prime} 22^{\prime \prime} \rightarrow 44^{\circ} 01^{\prime} 04^{\prime \prime} \rightarrow 594 ;$ Madinah- $1 \rightarrow 24^{\circ} 37^{\prime}$ $38^{\prime \prime} \rightarrow 39^{\circ} 54^{\prime} 08^{\prime \prime} \rightarrow 821$; Madinah- $\rightarrow 24^{\circ} 37^{\prime} 38^{\prime \prime} \rightarrow 39^{\circ} 54^{\prime} 08^{\prime \prime} \rightarrow 821$. 


\subsection{Morphological Characteristics}

The duckweed clones were transferred to a polypropylene container $\left(15 \times 10.5 \times 7.5 \mathrm{~cm}^{3}\right)$ filled with $750 \mathrm{~mL}$ of half-strength Hoagland solution. Three replicates were represented in each clone. Two weeks after establishment, from each replicate, ten plants for each clone were harvested. The following data were recorded, according to Ceschin et al. [30] as follows: qualitative characteristics (such as frond shape, symmetry, color, apex, and turions), while quantitative characteristics (frond length $(\mathrm{mm})$, width $(\mathrm{mm})$, thickness of aerenchyma layers, number of contiguous fronds (n), length, width, number of roots, and root length) were used in the evaluation.

All data was subjected to the analysis of variance (ANOVA) for the quantitative morphological traits of the studied duckweed clones. Mean and standard deviation of the evaluated traits $(n=10$ samples and three replications, total $=30)$. Mean separation was based on Tukey HSD at the 0.05 probability level.

\subsection{Molecular Markers Analysis: DNA Barcoding}

Genomic DNA was extracted from a single plant from each replicated clones after grinding duckweed fronds in liquid nitrogen using a DNA extraction kit (Qiagen, Hilden, Germany), following the company's instructions. For DNA barcoding, six plastid markers (psbK-psbI, trnH-psbA, atpF-atpH, matK, rpoC1, and rbcL) were used for DNA barcoding and identified different clones of duckweeds. The markers were selected based on duckweed reference sequences, as proposed by the plant working group of the Consortium for the Barcode of Life (CBOL), including three non-coding spacers (psbK-psbI, trnH-psbA, and atpF-atpH) and four plastid coding genes (matK, rpoB, rpoC1, and rbcL) were used to identify and characterize duckweed clones [31-33]. The amplicon sizes were estimated according to Wang et al. [8]. The PCR reaction comprised 50 ng genomic DNA, five pmol of each marker, 1X PCR Master Mix ((Promega, Fitchburg, WI, USA), and the volume completed to $25 \mu \mathrm{L}$. The PCR reaction was set as follows: initial denaturation at $94{ }^{\circ} \mathrm{C}$ for $5 \mathrm{~min}$, denaturation at $94^{\circ} \mathrm{C}$ for $1 \mathrm{~min}$, with the annealing temperature set for each marker, and extension at $72{ }^{\circ} \mathrm{C}$ for $1 \mathrm{~min}$ for 35 cycles. However, the final extension time was $72{ }^{\circ} \mathrm{C}$ for $5 \mathrm{~min}$. The PCR products were purified using Wizard SV gel and a PCR clean-up system (Promega, Fitchburg, WI, USA). The purified PCR samples were sent to Macrogen, South Korea (https:/ / www.macrogen.com/en/main/index.php) (accessed on 6 December 2020) for sequencing by ABI3730 automated sequencer using the same markers as in the PCR reactions. The strands were both sequenced and checked for ambiguous nucleotides. $30 \mathrm{bp}$ at the ends of each read were removed, the length of amplicon products was measured, and multiple DNA sequence alignments were generated using ClustalW alignment software [34,35]. The phylogenetic tree was constructed using MEGA $X$ to group the clones with following matrix: DNA weight matrix $=I U B$, transition weight $=0.50$, delay divergent cutoff $30 \%$ [36].

\subsection{Phylogenetic Analysis Based on DNA Sequence}

The evolutionary history was inferred by using the maximum likelihood method and the Tamura-Nei model [36]. The optimal tree with the sum of branch length $=10.41207259$ is shown. The evolutionary distances were computed using the maximum composite likelihood method and are in the units of the number of base substitutions per site. This analysis involved 82 nucleotide sequences with the following Genbank accession numbers: OK546023, OK571365, OK350360, OK350359, OK546024, OK350358, OK350361, OK350363, OK350362, OK546025, KJ921758, KJ136047, GU454305, GU454300, MG000445, GU454502, GU454494, GU454491, OK103562, OK383787, OK383788, OK103563, OK383786, OK383789, OK383790, OK247674, OK571366, OK247675, OK095301, OK375248, OK546020, OK571364, AY034197.1, OK375249, OK546021, OK546026, OK375250, KX526519, OK546022, KP017666.1, OK376426, Ok546019, OK376427, OK493446, KF726306.1, OK493447, KP017715.1, OK493448, OK493449, OK493450, KP017720, OK493451, OK493452, KP017721.1, OK095300, OK383787, OK598959, KX212889, OK598958, OK598957, OK598956, KJ630548, OK598955, KJ630555, OK598954, 
OK247676, KJ630513.1, OK571367, OK598946, OK598947, OK598949, JN114815.1, OK598948, GQ436374, OK598951, OK598952, OK571368, AY034223, OK571369, OK598950, and KC584885. All ambiguous positions were removed for each sequence pair (pairwise deletion option). There were a total of 1611 positions in the final dataset. Evolutionary analyses were conducted in MEGA X [37] using Matrix Representation with Parsimony method [38]. The numbers on the nodes represent the percentage of bootstrap values from the 1000 replicates.

\section{Conclusions}

This study characterized duckweed clones collected from ten different Saudi Arabia regions at both morphological and molecular levels. The results should help to inform research on the indigenous duckweed clones adapted to the climate of Saudi Arabia. Three out of six plastid markers ( $t r n \mathrm{H}-p s b \mathrm{~A}, m a t K$, and $a t p \mathrm{~F}-a t p \mathrm{H})$ helped to identify the dominant duckweed species in Saudi Arabia. Evaluation of performing L. punctata, L. perpusilla, and S. polyryiza clones in environments such as in Saudi Arabia is needed for future uses such as animal feed supplies and bioremediation programs.

Supplementary Materials: The following are available online at https:/ /www.mdpi.com/article/10 .3390 / plants10112438/s1. Figure S1: Multiple nucleotide sequence alignments of the concatenated sequences of psbK-psbI, trnH-psbA, and atpF-atpH intergenic spacer region, and matK, rpoC1, and $r b c L$ genes generated using ClustalW alignment software. The identical nucleotides are shaded in black; Figure S2: Divergence score matrix of the concatenated sequences of psbK-psbI, trnH$\mathrm{psbA}$, and atpF-atpH intergenic spacer region, and $m a t K, r p o C 1$, and $r b c L$ gene, based on a ClustalW alignment with the BLOSUM62 matrix; Table S1: All sequences with their accessions number used for species identification.

Author Contributions: Conceptualization, M.A.-D. and S.A.; methodology, M.A.-D. and A.A.A.; validation, M.A.; formal analysis, M.A.-D.; data curation, A.A.A.; writing-original draft preparation, M.A.-D. and H.M.; writing-review and editing, H.M. All authors have read and agreed to the published version of the manuscript.

Funding: This research was funded by the Deanship of Scientific Research in King Saud University, the initiative of the DSR Graduate Students Research Support (GSR).

Institutional Review Board Statement: Not applicable.

Informed Consent Statement: Not applicable.

Data Availability Statement: All the data supporting this article were included in the main text.

Conflicts of Interest: The authors declare no conflict of interest. The funders had no role in the study's design, in the collection, analyses, or interpretation of data, in the manuscript's writing, or in the decision to publish the results.

\section{References}

1. Gupta, C.; Prakash, D. Duckweed: An effective tool for phytoremediation. Toxicol. Environ. Chem. 2013, 95, 1256-1266. [CrossRef]

2. Cheng, J.J.; Stomp, A.M. Growing Duckweed to recover nutrients from Wastewaters and for production of fuel ethanol and animal feed. Clean Soil Air Water 2009, 37, 17-26. [CrossRef]

3. Sońta, M.; Rekiel, A.; Batorska, M. Use of Duckweed (Lemna L.) in sustainable livestock production and aquaculture-A review. Ann. Anim. Sci. 2019, 19, 257-271. [CrossRef]

4. Les, D.H.; Landolt, E.; Crawford, D.J. Systematics of the Lemnaceae (duckweeds): Inferences from micromolecular and morphological data. Plant Syst. Evol. 1997, 204, 161-177. [CrossRef]

5. Crawford, D.J.; Landolt, E.; Les, D.H. An allozyme study of two sibling species of Lemna (Lemnaceae) with comments on their morphology, ecology and distribution. Bull. Torrey Bot. Club 1996, 123, 1-6. [CrossRef]

6. Crawford, D.J.; Landolt, E.; Les, D.H.; Archibald, J.K.; Kimball, R.T. Allozyme variation within and divergence between Lemna gibba and L. disperma: Systematic and biogeographic implications. Aquat. Bot. 2005, 83, 119-128. [CrossRef]

7. An, D.; Li, C.; Zhou, Y.; Wu, Y.; Wang, W. Genomes and transcriptomes of duckweeds. Front. Chem. 2018, 6, 230. [CrossRef]

8. Wang, W.; Wu, Y.; Yan, Y.; Ermakova, M.; Kerstetter, R.; Messing, J. DNA barcoding of the Lemnaceae, a family of aquatic monocots. BMC Plant Biol. 2010, 10, 205. [CrossRef]

9. Bog, M.; Appenroth, K.-J.; Sree, K.S. Duckweed (Lemnaceae): Its molecular taxonomy. Front. Sustain. Food Syst. $2019,3,117$. [CrossRef] 
10. Masrahi, Y.S.; Al-Turki, T.A.; Sayed, O.H. Wolffiella hyalina (Delile) Monod (Lemnaceae)—A new record for the flora of Saudi Arabia. Feddes Rep. 2010, 121, 189-193. [CrossRef]

11. Landolt, E. Key to the Determination of Taxa within the Family of Lemnaceae; Geobotanischen Institutes der Eidg. Technische Hochschule, Stiftung Rübel: Zurich, Switzerland, 1980; pp. 13-21.

12. Les, D.H.; Crawford, D.J.; Landolt, E.; Gabel, J.D.; Kimball, R.T. Phylogeny and systematics of Lemnaceae, the duckweed family. Syst. Bot. 2002, 27, 221-240.

13. Azer, S. Taxonomic revision of genus Lemna L. (lemnaceae gray) in Egypt. Ann. Agric. Sci. 2013, 58, 257-263. [CrossRef]

14. Bog, M.; Baumbach, H.; Schween, U.; Hellwig, F.; Landolt, E.; Appenroth, K.J. Genetic structure of the genus Lemna L. (Lemnaceae) as revealed by amplified fragment length polymorphism. Planta 2010, 232, 609-619. [CrossRef] [PubMed]

15. Klaus, J.; Nikolai, B.; Eric, L. Telling duckweed apart: Genotyping technologies for the Lemnaceae. Chin. J. Appl. Environ. Biol. 2013, 19, 1-10. [CrossRef]

16. Bog, M.; Schneider, P.; Hellwig, F.; Sachse, S.; Kochieva, E.Z.; Martyrosian, E.; Landolt, E.; Appenroth, K.-J. Genetic characterization and barcoding of taxa in the genus Wolffia Horkel ex Schleid. (Lemnaceae) as revealed by two plastid markers and amplified fragment length polymorphism (AFLP). Planta 2013, 237, 1-13. [CrossRef]

17. Zhang, J.; Azizullah, A. Genetic Diversity and DNA Barcoding in the Duckweed Family. In The Duckweed Genomes; Springer: Cham, Switzerland, 2020; pp. 59-65.

18. Xue, H.; Xiao, Y.; Jin, Y.; Li, X.; Fang, Y.; Zhao, H.; Zhao, Y.; Guan, J. Genetic diversity and geographic differentiation analysis of duckweed using inter-simple sequence repeat markers. Mol. Biol. Rep. 2012, 39, 547-554. [CrossRef]

19. Sieben, E. The status and distribution of vascular plants (Magnoliophyta, Lycophyta, Pteridophyta). In The Status and Distribution of Freshwater Biodiversity in Southern Africa; Darwall, W., Smith, K.G., Tweddle, D., Skelton, P., Eds.; IUCN: Gland, Switzerland, 2009; pp. 83-98.

20. Ding, Y.; Fang, Y.; Guo, L.; Li, Z.; He, K.; Zhao, Y.; Zhao, H. Phylogenic study of Lemnoideae (duckweeds) through complete chloroplast genomes for eight accessions. PeerJ 2017, 5, e4186. [CrossRef]

21. Tippery, N.; Les, D.; Crawford, D. Evaluation of phylogenetic relationships in Lemnaceae using nuclear ribosomal data. Plant Biol. 2015, 17, 50-58. [CrossRef]

22. Borisjuk, N.; Chu, P.; Gutierrez, R.; Zhang, H.; Acosta, K.; Friesen, N.; Sree, K.; Garcia, C.; Appenroth, K.; Lam, E. Assessment, validation and deployment strategy of a two-barcode protocol for facile genotyping of duckweed species. Plant Biol. 2015, 17, 42-49. [CrossRef]

23. Landolt, E. Biosystematic investigations in the family of duckweeds (Lemnaceae). The family of Lemnaceae a monographic study. Veroff Geobot. Inst. ETH 1986, 71, 1-563.

24. Xu, Y.; Ma, S.; Huang, M.; Peng, M.; Bog, M.; Sree, K.S.; Appenroth, K.-J.; Zhang, J. Species distribution, genetic diversity and barcoding in the duckweed family (Lemnaceae). Hydrobiologia 2015, 743, 75-87. [CrossRef]

25. Halder, S.; Venu, P. Lemna landoltii sp. nov. (Lemnaceae) from India. Taiwania 2012, 58, 12-14.

26. Les, D.H.; Crawford, D.J. Landoltia (Lemnaceae), a new genus of duckweeds. Novon 1999, 9, 530-533. [CrossRef]

27. Wang, W.; Haberer, G.; Gundlach, H.; Gläßer, C.; Nussbaumer, T.; Luo, M.; Lomsadze, A.; Borodovsky, M.; Kerstetter, R.; Shanklin, J. The Spirodela polyrhiza genome reveals insights into its neotenous reduction fast growth and aquatic lifestyle. Nat. Commun. 2014, 5, 3311. [CrossRef]

28. Jordan, W.C.; Courtney, M.W.; Neigel, J.E. Low levels of intraspecific genetic variation at a rapidly evolving chloroplast DNA locus in North American duckweeds (Lemnaceae). Am. J. Bot. 1996, 83, 430-439. [CrossRef]

29. Li, T. Annual Variation of Meteorological Radiation in Hainan Island. Meteorol. Mon. 2002, 28, 45-47.

30. Ceschin, S.; Leacche, I.; Pascucci, S.; Abati, S. Morphological study of Lemna minuta Kunth, an alien species often mistaken for the native L. minor L. (Araceae). Aquat. Bot. 2016, 131, 51-56. [CrossRef]

31. CBOL Plant Working Group; Hollingsworth, P.M.; Forrest, L.L.; Spouge, J.L.; Hajibabaei, M.; Ratnasingham, S.; van der Bank, M.; Chase, M.W.; Cowan, R.S.; Erickson, D.L. A DNA barcode for land plants. Proc. Natl. Acad. Sci. USA 2009, 106, 12794-12797.

32. Lahaye, R.; Savolainen, V.; Duthoit, S.; Maurin, O.; Van der Bank, M. A test of psbK-psbI and atpF-atpH as potential plant DNA barcodes using the flora of the Kruger National Park (South Africa) as a model system. Nat. Preced. 2008. [CrossRef]

33. Kress, W.J.; Erickson, D.L. A two-locus global DNA barcode for land plants: The coding $r b c$ Lene complements the non-coding trnH-psbA spacer region. PLoS ONE 2007, 2, e508. [CrossRef]

34. Thompson, J.D.; Higgins, D.G.; Gibson, T.J. CLUSTAL W: Improving the sensitivity of progressive multiple sequence alignment through sequence weighting, position-specific gap penalties and weight matrix choice. Nucleic Acids Res. 1994, 22, 4673-4680. [CrossRef] [PubMed]

35. Thompson, J.D.; Gibson, T.J.; Higgins, D.G. Multiple sequence alignment using ClustalW and ClustalX. Curr. Protoc. Bioinform. 2003, 1, 2-3. [CrossRef]

36. Tamura, K.; Dudley, J.; Nei, M.; Kumar, S. MEGA4: Molecular evolutionary genetics analysis (MEGA) software version 4.0. Mol. Biol. Evol. 2007, 24, 1596-1599. [CrossRef] [PubMed]

37. Kumar, S.; Stecher, G.; Li, M.; Knyaz, C.; Tamura, K. MEGA X: Molecular evolutionary genetics analysis across computing platforms. Mol. Biol. Evol. 2018, 35, 1547. [CrossRef] [PubMed]

38. Ragan, M.A. Phylogenetic inference based on matrix representation of trees. Mol. Phylogenetics Evol. 1992, 1, 53-58. [CrossRef] 